\title{
Trauma Masa Anak, Hubungan Romantis, dan Kepribadian Ambang
}

\author{
Childhood Trauma, Romantic Relationship, \\ and Borderline Personality
}

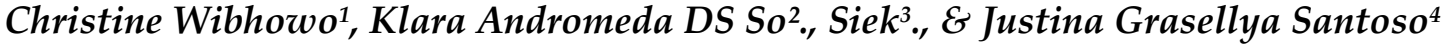 \\ 1,2,3,4Fakultas Psikologi Universitas Katholik Soegijapranata Semarang
}

\begin{abstract}
People with borderline personality features (BPF) are characterized by impulsive, emotionally unstable, have unsafe sexual activity, and other actions that are at risk to commit suicide. Although some of the behavior is not included in crime, if there is no prevention, the BPF will endanger itself and its environment. This study aims to determine the relationship between childhood trauma, a romantic relationship, with BPF. The hypothesis are, 1) there is a relationship between childhood trauma and BPF;2) there is relationship between romantic a relationships and BPF. This study using 77 participant wives aged 20-40 years. Collecting data using Borderline Personality Scale, Childhood Trauma Scale, and Romantic relation Scale. Data analysis with product moment. The result of this study are 1) there is a relationship between childhood trauma and borderline personality $(\mathrm{r}=0.6, \mathrm{p}<0.01) ; 2)$ there is relationship between romantic relationship and borderline personality $(\mathrm{r}=-0.5=\mathrm{p}<0.01)$.
\end{abstract}

Keywords: borderline personality; childhood trauma; romantic relationships

Abstrak. Orang dengan kepribadian ambang (KA) ditandai dengan impulsif, emosional tidak stabil, memiliki aktivitas seksual yang tidak aman, dan tindakan lain yang berisiko untuk melakukan bunuh diri. Meskipun beberapa perilaku tidak termasuk dalam kejahatan, tetapi jika tidak ada pencegahan, maka KA akan membahayakan dirinya dan lingkungannya. Penelitian ini bertujuan untuk mengetahui hubungan trauma masa kecil, hubungan romantis, dengan KA. Hipotesisnya adalah 1) ada hubungan antara trauma masa kanak-kanak dan KA; 2) ada hubungan antara hubungan romantis dan KA. Partsipan dalam penelitian ini 77 istri berusia 20-40 tahun. Data dikumpulkan dengan menggunakan tiga skala, yaitu Skala Kepribadian Ambang, Skala Trauma Masa Anak, dan Skala Hubungan Romantis. Analisis data menggunakan product moment. Hasil penelitian ini, 1) ada hubungan positif yang signifikan antara trauma masa kanak-kanak dan kepribadian ambang $(\mathrm{r}=0.6, \mathrm{p}<0,01) ; 2)$ ada hubungan negatif yang signifikan antara hubungan romantis dan kepribadian ambang $\quad(r=-0.5=p$ $<0,01)$.

Kata kunci: hubungan romantis; kepribadian ambang; trauma masa anak

Istilah kepribadian ambang (KA) pertama kali dicetuskan oleh seorang terapis yang beraliran Psikoanalisa, bernama Adolf

\footnotetext{
${ }^{1}$ Korespondensi mengenai artikel ini dapat melalui: christine.wibhowo@mail.ugm.ac.id;
}

Sterm (dalam Keppen \& Kimberly, 2014). Seseorang dapat dikatakan mengalami KA jika tidak dapat digolongkan ke dalam 
gangguan neurosis maupun psikosis. Pada pasiennya yang memiliki kepribadian ambang ini, Sterm mengindentifikasikan adanya sifat negatif pada saat proses terapi karena sikapnya yang berubah-ubah. Dalam DSM-5 atau Diagnostic and Statistical Manual of Mental Disorders (American Psychiatric Association, 2013), kepribadian ambang didefinisikan sebagai suatu gangguan dengan kriteria ketidakstabilan dalam hubungan interpersonal, citra/gambaran diri yang kabur, dan impulsivitas yang diawali pada masa dewasa. Kepribadian ambang tergolong dalam gangguan kepribadian aksis II serta termasuk dalam gangguan kepribadian kelompok B, yaitu orang dengan perilaku yang terlalu dramatis, emosional, dan eratik/tidak menentu. Diagnosis ini baru bisa ditegakkan apabila orang tersebut telah berusia 18 tahun. Berdasarkan data dari DSM-5 (APA, 2013), kriteria KA yang dimiliki oleh seseorang dapat menurun dengan bertambahnya usia seseorang. Hal tersebut disebabkan dengan bertambahnya usia, seseorang dengan KA akan mulai memahami peristiwa-peristiwa yang menyebabkan ia menjadi KA, dan ia berusaha menghindari peristiwa-peristiwa tersebut. Hal ini sejalan dengan hasil penelitian dari Chan, et al. (2012) yang menyimpulkan bahwa ada perbedaan KA pada kelompok usia 20 tahun dan kelompok usia 30 tahun ke atas. Selain itu menurut DSM-5 (APA, 2013), 75\% penderita KA adalah wanita. Oleh karena itu, penelitian ini menggunakan partisipan wanita dengan usia 20-40 tahun yang dapat mewakili kedua kelompok usia tersebut.

Menurut Kernberg dan Michels (2009), jumlah orang yang mengalami KA sebesar $4 \%$ dalam populasi. Penyebab KA bisa karena faktor neurobiologi dan faktor psikologis. Di Indonesia, belum diketahui data pasti mengenai jumlah penderita kepribadian ambang, namun jumlahnya diperkirakan semakin banyak, seiring dengan jumlah kasus kekerasan yang semakin meningkat.

Menurut catatan Komnas Perempuan (2016), kasus kekerasan terhadap perempuan mengalami peningkatan setiap tahunnya. Jenis kekerasan yang paling banyak yaitu kekerasan pada lingkungan personal. Hal ini disimpulkan bahwa kekerasan yang dilakukan disebabkan oleh faktor kepribadian individu yang tidak stabil dan tidak semata-mata disebabkan oleh faktor ekonomi dan hukum. Pelaku kekerasan, terutama kekerasan seksual, jika sampai dilaporkan oleh korban maka diduga perilaku itu telah diterima oleh korban beberapa kali. Jadi pelaku maupun korban memiliki kepribadian yang impulsif, hubungan interpersonal yang tidak baik, dan emosi yang tidak stabil. Menurut Distel (2009), sebaiknya tidak mengabaikan adanya perilaku kekerasan, perilaku yang emosional, sering kehilangan pekerjaan, penyalahgunaan zat, dan perilaku mudah menikah-mudah cerai yang ditunjukkan oleh individu karena perilaku itu bisa saja merupakan tandatanda adanya KA.

Berdasar penelitian yang dilakukan oleh Kitamura dan Nagata (2014) disimpulkan bahwa trauma masa anak merupakan determinan utama untuk KA, depresi, dan perilaku bunuh diri. Disampaikan juga bahwa dibanding gangguan kepribadian yang lain, maka trauma masa anak paling banyak berhubungan dengan KA.

Penelitian tentang hubungan trauma masa anak (TMA) dengan kepribadian ambang memang telah banyak dilakukan sebelumnya. Di antaranya dilakukan oleh Kaehler dan Freyd (2012); Kujipers, Van Der Knaap, Winkel, Pemberton, dan Baldry (2011); dan Rasonabe (2013). Penelitian- 
penelitian yang telah dilakukan membuktikan bahwa trauma masa anak berperan pada terjadinya kepribadian ambang. Menurut Minzenberg, Poole, dan Vinogradov (2008), trauma masa anak meliputi beberapa aspek, diantaranya kekerasan fisik, kekerasan seksual, kekerasan emosional, penolakan fisik, penolakan emosional, dan menyaksikan kekerasan.

Berdasar data yang diperoleh, Kitamura dan Nagata (2014) menyimpulkan bahwa $90 \%$ individu yang mengalami kekerasan fisik dan seksual saat usia anak-anak akan mengalami KA. Rasonabe (2013) juga menyatakan bahwa faktor keluarga (hubungan dengan ayah, ibu, dan saudara) sangat berperan terhadap terjadinya KA. Seorang anak yang mengalami kekerasan (yang dilakukan oleh orang yang diharapkan melindunginya) akan cenderung untuk memandang dunia menjadi tidak nyaman dan tidak aman. Oleh karena itu, ia mencoba melindungi diri sendiri dengan bersikap agresif.

Hasil penelitian dari Kujipers, et al. (2011) menunjukkan bahwa trauma masa anak sangat berperan terhadap KA, terutama pada kriteria bunuh diri. Seorang anak yang sering mendapat kekerasan akan menganggap bahwa dirinya tidak berharga. Selain itu, ia akan menganggap bahwa memang kekerasan merupakan suatu jalan untuk memecahkan persoalan. Jika ia mengalami persoalan maka ia akan melukai diri sendiri, bahkan akan melakukan bunuh diri untuk melupakan kesedihannya. Individu yang melakukan hal tersebut secara berulang-ulang akan memiliki kriteria KA.

Berdasarkan studi meta analisis yang penulis lakukan pada tahun 2015 , terhadap kepribadian ambang dan trauma masa anak, memang dari 24 penelitian yang cukup meyakinkan, diketahui ada hubungan antara trauma masa anak (TMA) dan kepribadian ambang (KA). Dari hasil studi meta-analisis ditemukan bahwa koerelasi antara TMA dan KA sebesar 0,3 yang berarti hubungannya kuat. Akan tetapi karena ada kesalahan pengukuran sebesar $11,88 \%$, maka masih ada faktor lain yang juga berhubungan dengan KA. Selain itu, penelitian tentang hubungan trauma masa anak dan KA masih perlu dilakukan karena belum ada penelitian tersebut di Indonesia.

Selain trauma masa anak, faktor lain yang diduga berperan terhadap KA yaitu kelekatan. Kelekatan berkembang selama hidup. Pada masa anak-anak, figur lekatnya yaitu orangtuanya. Kelekatan berkembang sesuai usia individu. Setelah individu dewasa maka figur lekat dan jenis dukungannya akan berubah, misalnya berubah menjadi kelekatan dengan pasangan. Konsep kelekatan dengan pasangan ini disebut dengan hubungan romantis (Hazan \& Zeifman, 2016). Aspekaspek dalam hubungan romantis menurut Sternberg (Compton \& Hoffman, 2013), yaitu melibatkan hubungan cinta romantis, keintiman, dan komitmen.

Nanu (2015) dalam penelitiannya membuktikan bahwa seseorang yang memiliki kelekatan akan belajar dari hubungannya dengan subjek lekatnya. Ia akan memiliki rasa aman sehingga membuat individu mampu mengatur emosi dirinya dan hubungan dengan lingkungan sosialnya. Kemampuan ini akan membuat individu lebih memiliki konsep dan harga diri yang baik. Dengan demikian, salah satu kriteria dari KA yaitu citra diri dan konsep diri yang kabur, akan berkurang jika seseorang memiliki hubungan romantis dengan pasangannya. Dengan demikian pula, dapat diketahui bahwa kelekatan di masa dewasa atau 
hubungan romantis dengan pasangan akan membuat seseorang terhindar dari gangguan kepribadian, seperti KA.

Berdasar beberapa teori tersebut maka hipotesis dalam penelitian ini ada dua, yaitu 1) ada hubungan antara trauma masa anak dan kepribadian ambang; 2) ada hubungan antara hubungan romantis dan kepribadian ambang.

\section{Metode}

Terdapat tiga variabel yang digunakan dalam penelitian ini, yaitu: trauma masa anak, hubungan romantis, dan kepribadian ambang. Pada penelitian ini, semua skala yaitu Skala KA, Skala Trauma, dan Skala Hubungan Romantis, disusun sendiri oleh peneliti. Masing-masing skala disusun berdasar aspek-aspek sesuai teori. Setelah dibuat aitem maka diujicobakan kepada 13 partisipan, untuk memeriksa bahasa agar mudah dipahami. Selanjutnya aitem disusun kembali dan diujicobakan kepada 77 partisipan, pada bulan Juli 2016, untuk diuji validitas dan reliablitasnya.

Kepribadian ambang diukur menggunakan Skala Kepribadian Ambang. Aitem pada skala ini disusun berdasarkan pada 9 kriteria dari DSM-IV. Contoh aitem dalam skala ini yaitu "saya pernah mencoba melukai diri sendiri untuk diperhatikan orang lain" dan "saya pernah melakukan satu atau lebih hal-hal berikut: melakukan hubungan seks yang tidak aman, makan dalam jumlah tak terkontrol".

Data hubungan romantis diperoleh dari Skala Hubungan Romantis, yang aspek-aspeknya meliputi hubungan romantis, keintiman, dan komitmen (Compton \& Hoffman, 2013), Contoh aitemnya adalah "saya menyukai kontak fisik dengan suami, seperti memeluk dan menciumnya" dan "ada saatnya saya merasa suami tak mengerti saya".
Skala Trauma Masa Anak disusun berdasarkan enam aspek, yaitu kekerasan emosional, kekerasan seksual, kekerasan fisik, pengabaian emosional, pengabaian fisik, dan menyaksikan kekerasan (Minzenberg, et al., 2008). Aitem dalam skala ini misalnya "orang tua mengatakan bahwa saya bukanlah anak yang diinginkan" dan "orang tua pernah mencoba melukai saya".

Partisipan dalam penelitian ini, yaitu para isteri sehingga bahasa juga diujicobakan kepada para isteri (13 orang). Berikutnya yaitu mengukur persetujuan/ kesesuaian antar penilai dengan uji CVR (Content Validity Ratio), berdasar metode Lawshe dan menghitung indeks validatas isi (content validity index/CVI (Azwar, 2014).

Tabel 1.

Rangkuman hasil CVI semua skala

\begin{tabular}{llc}
\hline \multicolumn{1}{c}{ Skala } & \multicolumn{1}{c}{ CVI } & Jumlah Aitem \\
\hline Kepribadian Ambang & 0,92 & 36 \\
Trauma Masa Anak & 0,91 & 24 \\
Hubungan Romantis & 0,9 & 20 \\
\hline
\end{tabular}

Hasilnya, semua aitem dalam skala dapat dipahami maknanya dengan benar oleh partisipan dan memiliki validitas isi yang baik. Beberapa aitem dalam Skala Hubungan Romantis diberi contoh sehingga lebih mudah dipahami. Contoh aitem dalam Skala Hubungan Romantis yang berubah, misalnya "Saya menikmati kontak fisik dengan suami" berubah menjadi "saya menyukai kontak fisik dengan suami, seperti memeluk dan menciumnya."

Populasi dalam penelitian ini, yaitu wanita yang berstatus istri yang berada pada usia dewasa muda 20-40 tahun. Hal ini karena seperti yang telah dijelaskan sebelumnya bahwa $75 \%$ orang yang mengalami KA yaitu wanita, dengan usia 20-40 tahun. Dalam penelitian ini terdapat Skala Romantis sehingga partisipan dalam 
penelitian ini berstatus sudah menikah (sebagai istri). Sebagian besar partisipan (52 orang) dalam penelitian ini ditemui langsung oleh peneliti untuk mengisi skala. Dua puluh lima partisipan mengisi skala melalui online. Keuntungan menggunakan skala online antara lain, partisipan merasa lebih nyaman karena merasa kerahasiaan terjaga dan dapat mengisi skala sesuai dengan jadwal mereka sendiri. Selain itu, dengan media online maka tidak ada aitem yang terlewat untuk dijawab, karena sudah diatur dengan program. Kelemahan menggunakan online, yaitu tidak ada jaminan bahwa partisipan sendiri yang mengisi skala walaupun untuk mengantipasi hal ni, partisipan diminta untuk menyebutkan alamat email. Selain itu, partisipan bisa saja mengisi jawaban yang tidak sesuai dengan kenyataan yang ia hadapi. Kelemahan ini juga terjadi pada pengisian skala secara tatap muka.

\section{Hasil}

Data yang dapat dianalisis berjumlah 77 yang kemudian diuji asumsi. Hasilnya aitem pada Skala Trauma Masa Anak sesuai untuk mengukur trauma masa anak dan reliabel. Aitem pada Skala Kepribadian Ambang sesuai dan reliabel, demikian juga aitem pada Skala Hubungan Romantis. Dengan demikian semua skala dapat dengan tepat mengukur aspek-aspeknya (Tabel 1). Selanjutnya untuk menguji hubungan variabel maka data diuji normalitasnya. Hasilnya menunjukkan bahwa semua data termasuk normal (Tabel 2). Selain uji validitas dan reliabilitas, data dalam penelitian ini juga diuji linearitasnya dan hasilnya linear (Tabel 3).

Berikutnya, data dianalisis dengan menggunakan program SPSS. Dari hasil analisis data ditemukan bahwa ada korelasi antara trauma dan kepribadian ambang $(\mathrm{r}=0,6 ; \mathrm{p}<0,01)$ atau dengan kata lain ada hubungan positif yang sangat signifikan antara trauma masa anak

Tabel 2.

Hasil uji asumsi skala

$\mathrm{N}=77$

\begin{tabular}{|c|c|c|c|}
\hline Skala & $\begin{array}{l}\text { Indeks Daya } \\
\text { Diskriminasi }\end{array}$ & $\begin{array}{c}\text { Estimasi } \\
\text { Reliabilitas }\end{array}$ & $\begin{array}{l}\text { Uji Normalitas Kolmogorov-Smirnov test } \\
\text { (K-S test) }\end{array}$ \\
\hline Trauma masa anak & $0,398-0,726$ & 0,914 & $\begin{array}{l}\text { K-S tes }=1,071, p>0,05 \\
\text { Berarti normal }\end{array}$ \\
\hline Kepribadian ambang & $0,283-0,767$ & 0,911 & $\begin{array}{l}\text { K-S-tes }=0,829, p>0,05 \\
\text { Berarti normal }\end{array}$ \\
\hline Hubungan romantis & $0,481-0,775$ & 0,93 & $\begin{array}{l}\text { K-S tes }=0,846, p>0,05 \\
\text { Berarti normal }\end{array}$ \\
\hline
\end{tabular}

Tabel 3.

Uji linearitas

\begin{tabular}{ccc}
\hline Variabel & Nilai F & Keterangan \\
\hline Trauma masa anak dan kepribadian ambang & $35,320, \mathrm{p}<0,01$ & Linier \\
Hubungan romantis dan kepribadian ambang & $34,27, \mathrm{p}<0,01$ & Linier \\
\hline
\end{tabular}


dengan kepribadian ambang. Korelasi antara hubungan romantis dan kepribadian ambang juga terbukti $(r=-0,5 ; \mathrm{p}<$ $0,01)$. Ini berarti ada hubungan negatif yang sangat signifikan antara hubungan romantis dengan kepribadian ambang.

\section{Diskusi}

Dari analisis data ditemukan bahwa semakin tinggi trauma masa anak maka semakin tinggi kepribadian ambang. Sebaliknya, semakin rendah trauma masa anak yang dialami, maka semakin rendah pula kepribadian ambangnya. Hal ini sesuai dengan hasil penelitian yang dilakukan oleh Kitamura dan Nagata (2014). Trauma yang terjadi pada masa anak akan terbawa sampai dewasa dan memengaruhi pandangan orang tersebut mengenai dirinya maupun orang lain. Trauma masa anak dapat meliputi kekerasan fisik, kekerasan seksual, kekerasan emosional, pengabaian emosional, pengabaian fisik, dan menyaksikan tindakan kekerasan. Riggs (2010) juga menyampaikan bahwa pola asuh yang membuat anak mengalami trauma, yaitu pengasuhan yang sering mengabaikan pengalaman emosional anak, dingin, dan tidak konsisten. Dalam DSM-5 (APA, 2013) dinyatakan bahwa jika individu mengalami trauma di masa anak maka ia akan mengalami luka hati. Untuk menutup luka hatinya individu akan melakukan perilaku berisiko agar mendapat perhatian dari orang lain. Perilaku yang dimunculkan masuk dalam kriteria KA.

Anak yang mengalami kekerasan fisik akan mengembangkan perasaan negatif seperti ketakutan, sakit hati, perasaan tertolak/tidak diterima oleh lingkungan, yang menyebabkan di masa dewasa anak cenderung senang mencari keintiman dari orang lain dan melakukan segala cara untuk menghindari perasaan ditolak/takut ditinggalkan oleh orang lain. Begitu pula dengan anak yang mengalami kekerasan seksual sangat mungkin diancam oleh pelakunya untuk tetap diam dan tidak menceritakan pengalaman tersebut kepada siapapun (Kitamura \& Nagata, 2014). Dengan demikian, ia sangat takut dan malu namun tak dapat mengungkapkan perasaannya sehingga akibatnya proses pengolahan emosi dan cara mengekspresikan emosi (regulasi emosi) dalam diri anak tersebut akan terganggu. Penelitian dengan hasil yang sama juga dilakukan oleh Vermetten dan Spiegel (2014).

Hal ini juga senada dengan hasil penelitian dari Lestari, Faturochman, dan Kim (2010) yang menyimpulkan bahwa kepercayaan anak terhadap orang tua akan berkembang menjadi kepercayaan kepada orang lain dan kepercayaan pada diri sendiri. Dengan demikian, jika anak percaya terhadap orang tua maka kemampuan anak akan lebih optimal dan memandang dunia menjadi tempat yang aman. Beberapa hal yang dapat dilakukan agar anak percaya pada orang tua adalah sikap jujur, bijaksana, hangat, dan mendukung anak.

Selain trauma masa anak, faktor hubungan romantis juga berhubungan dengan KA. Hal ini sesuai dengan hasil penelitian dari Watkins (2011) yang meneliti tentang dua dimensi dari kelekatan, yaitu kelekatan dengan pola kecemasan dan kelekatan dengan pola penghindaran. Dua dimensi tersebut sama-sama berhubungan dengan KA. Jadi faktor kelekatan anak dan orang tua menjadi faktor yang penting untuk kesehatan psikis individu. Kelekatan di masa dewasa tidak lagi kepada orangtuanya namun kepada pasangannya atau hubungan romantis 
dengan pasangannya (Hazan \& Zeifman, 2016).

Dinamika yang sama terjadi pada hubungan romantis dengan KA. Saat hubungan romantis antara isteri dengan suaminya baik, maka isteri dapat merasa aman. Hubungan romantis yang baik itu misalnya mengetahui bahwa suami bisa mengerti dirinya tanpa harus bercerita, yakin bahwa suami akan menghiburnya di saat sedang sedih, dan tahu suaminya bisa diandalkan saat ia mengalami kesulitan.

Hasil peneltian ini menunjukkan bahwa nilai korelasi antara trauma masa anak dan hubungan romantis dengan KA sebesar 0,657. Dapat diasumsikan bahwa trauma dan hubungan romantis berperan sebesar $43 \%$ terhadap terjadinya kepribadian ambang. Dengan demikian, ada faktor lain yang berperan terhadap kepribadian ambang. Dari hasil wawancara terhadap sebagian partisipan penelitian dapat disimpulkan bahwa dukungan yang diperoleh dari lingkungan sekitar sangat membantu mereka dalam mengembangkan kepribadian. Kemampuan mereka dalam menangani persoalan (coping) juga membuat partisipan lebih bisa stabil sehingga kemungkinan kecenderungan terjadinya keperibadian ambang bisa berkurang. Tidak kalah pentingnya, yaitu faktor usia. Beberapa partisipan mengatakan bahwa sebenarnya mereka mungkin memiliki dorongan untuk impulsif namun dengan seiringnya waktu, maka mereka merasa harus lebih bijaksana. Dengan demikian, usia menjadi faktor yang dapat diperhitungkan dalam mengurangi adanya kepribadian ambang (Shea \& Edelen, 2010; Chan et al., 2012).

Penelitian ini akan lebih dapat memberi gambaran mengenai KA, jika partisipan dipilih berdasarkan kelompok usia, misalnya kelompok usia 20 tahun, 30 tahun, dan 40 tahun (Chan et al., 2012).
Dengan begitu, maka akan lebih diketahui tentang terapi yang tepat untuk individu dengan KA.

\section{Kesimpulan}

Dari hasil penelitian ini dapat disimpulkan bahwa ada hubungan antara trauma masa anak dan kepribadian ambang serta ada hubungan antara hubungan romantis dan kepribadian ambang. Dengan demikian diketahui bahwa untuk mencegah terjadinya KA, dapat dilakukan dengan melupakan trauma masa anak dan fokus untuk membina hubungan romantis dengan pasangan. Keterbatasan penelitian ini yaitu tidak mengelompokkan partisipan berdasar kelompok usia, padahal usia berperan penting dalam terjadinya kepribadian ambang.

\section{Saran}

Dengan melihat hasil penelitian maka disarankan khususnya kepada para orang tua untuk tidak melakukan kekerasan dalam bentuk apapun kepada anak karena akan menimbulkan rasa trauma yang berlanjut pada terjadinya kepribadian ambang. Para wanita juga disarankan untuk tidak terlalu fokus pada masalahmasalah di masa lalu namun meningkatkan keromantisan hubungan dengan pasangannya. Hal ini dapat mencegah terjadinya kepribadian ambang. Untuk peneliti selanjutnya dapat meneliti tentang peran dukungan sosial, usia, dan penanganan masalah (coping) terhadap kepribadian ambang.

\section{Kepustakaan}

American Psychiatric Association (APA). (2013). Diagnostic and statistical manual of mental disorders (DSM-5). Washington, DC: APA Publisihing. 
Azwar, S. (2014). Penyusunan skala psikologi. Yogyakarta: Pustaka Pelajar.

Chan, W., McCrae, R. R., Fruyt, F. D., Lee, J., Lockenhoff, C. E., \& DeBolle, M. (2012). Stereotypes of age differences in personality traits: Universal and accurate?. J Pers Soc Psychol, 103(6), 1050-1066. doi: 10.1037/a0029712.

Compton, W. C., \& Hoffman, E. (2013). Positive psychology: The science of happiness and flourishing. America: Wadsworth Cengage Learning

Distel, M. (2009). Individual differences in borderline personality traits: A genetic perspective. Amsterdam: Drukkerij Van Werkhoven.

Hazan, C., \& Zeifman, D. (2016). Pair bonds as attachment: Evaluating the evidence. Dalam J. Cassidy \& P. Shaver (Eds.). Handbook of Attachment: Theory, research, and clinical application. New York: Guilford.

Kaehler, L. A., \& Freyd, J. J. (2012). Betrayal trauma and borderline personality characteristics: Gender differences. Psychological Trauma: Theory, Research, Practice, and Policy, 4(4), 379-385. doi: 10.1037/a0024928

Kernberg, O. F., \& Michels, R. (2009). Borderline personality disorder. The American Journal of Psychiatry. 166(5), 505-508. doi: 10.1176/appi.ajp.2009.09020263

Keppen \& Kimberly. (2014). The effects of childhood abuse on the etiology of borderline personality disorder. A research paper presented to the faculty of the Adler Graduate School.

Kitamura, T., \& Nagata, T. (2014). Suicidal ideation among Japanese undergraduate students: Relationships with borderline personality trait, depressive mood, and childhood abuse experiences. American Journal of Psychology and Behavioral Sciences, 1(2), 7-13.

Komnas Perempuan. (2016). Siaran pers Komnas Perempuan catatan tahunan (Catahu) 2016. Diunduh dari http://www.komnasperempuan.go.id/ siaran-pers-komnas-perempuancatatan-tahunan-catahu-2016-7-maret2016/

Kujipers, K., Van Der Knaap, L., Winkel, F., Pemberton, A., \& Baldry, A. (2011). Borderline traits and symptoms of post-traumatic stress in a sample of female victims of intimate partner violence. Stress and Health, 27, 206-215.

Lestari, S., Faturochman., \& Kim, U. (2010). Trust in parent-child relationship among undergraduate students: Indigenous psychological analysis. Jurnal Psikologi, 37(2).

Minzenberg, M. J., Poole, J. H., \& Vinogradov, S. (2008). A neurocognitive model of Borderline Personality Disorder: Effects of childhood sexual abuse and relationship to adult attachment disturbance. Development and Psychopathology. USA: Cambridge University Press. 20.

Nanu, D. E. (2015). The Attachment relationship with emotional intelligence and weel-being. Journal of Experiental Psychoteraphy, 18, 70.

Rasonabe, M. B. (2013). Predisposed borderline personality disorder (PreBPD). ISS \& MLB. ISS. September 24-26, pp 1004.

Riggs, S. A. (2010). Childhood emotional abuse and the attachment system across the life cycle: What theory tell us. Journal of Aggression, Maltreatment, and Trauma, 19(1), 5-51.

Shea, T. M., \& Edelen, M. O. (2010). Improvement borderline disorder in 
relathonship to age. Acta Psychiatri Scand, 143-148.

Vermetten, E. \& Spiegel, D. (2014). Trauma and dissociation: Implications for borderline personality disorder. Curr
Psychiatry, 16(434), 1-10. doi: 10. 1007/ s11920-013-0434-8.

Watkins, C. D. (2011). Effect of maternal borderline personality disorder on romantic attachment in adolescent. Thesis. Knoxville: University of Tennessee. 